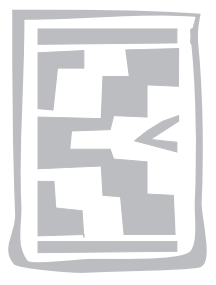

\title{
Canine babesiosis
}

J.P. SCHOEMAN

Department of Companion Animal Clinical Studies, Faculty of Veterinary Science, University of Pretoria Private Bag X04, Onderstepoort, 0110 South Africa

\begin{abstract}
SCHOEMAN, J.P. 2009. Canine babesiosis. Onderstepoort Journal of Veterinary Research, 76:5966

Babesiosis is a tick-borne disease affecting humans and many domestic and wild animals. Domestic animals showing appreciable morbidity and mortality include dogs, cats, cattle and horses. Both canine and feline babesiosis are diseases characterised by haemolytic anaemia, icterus and haemoglobinuria. Canine babesiosis can range from chronic or subclinical to peracute and fatal, depending on the virulence of the species and the susceptibility of the host. This paper deals with canine babesiosis with specific reference to pathogenesis, clinical findings, complications, diagnosis and treatment, as well as newly identified prognostic factors in Babesia rossi babesiosis.
\end{abstract}

\section{EPIDEMIOLOGY}

Babesiosis is a disease of worldwide significance and was first recognised in 1888 as a cause of fever, haemolytic anaemia, haemoglobinuria and death of cattle. Members of the genus Babesia readily parasitize the red blood cells of dogs, causing progressive anaemia. Canine babesia are morphologically classified into large and small forms, both exhibiting a worldwide distribution (Table 1). Babesia canis and another novel, as yet unnamed Babesia sp. detected in the USA (large Babesia) and Babesia gibsoni and Babesia annae (small Babesia) have been documented to infect dogs (Birkenheuer, Neel, Ruslander, Levy \& Breidschwerdt 2004). Three main species of large Babesia infect dogs, namely Babesia vogeli, $B$. canis and Babesia rossi. These three species are antigenically distinct, transmitted by different vectors and differ widely in pathogenicity and geographic distribution (Uilenberg, Franssen, Perie \& Spanjer 1989).

Babesia vogeli is the least pathogenic. It occurs in France, Australia, Japan, Brazil, South Africa and the USA and usually causes mild disease in adult dogs, but severe disease in some puppies (Matjila, Penzhorn, Bekker, Nijhof \& Jongejan 2004). Babesia canis is widespread in Europe (it affects more than 400000 dogs per year in France alone) and Asia and is of intermediate pathogenicity.

Babesia rossi occurs predominantly in southern Africa and is ostensibly the most virulent of the subspecies. Improved PCR techniques have lately allowed for better definition of these parasites (Matjila, Leisewitz, Jongejan \& Penzhorn 2008).

The smaller parasite, B. gibsoni occurs principally in the Middle East, southern Asia, Japan, North Africa, South America and is an emerging infectious disease in the USA, as well as having been detected lately in Italy, Hungary and Australia (Muhlnickel et al. 2002). A more virulent subspecies of $B$. gibsoni has recently been identified in California (Kjemtrup, Wainwright, Miller, Penzhorn \& Carreno 2006)

A Babesia microti-like piroplasma, B. annae (also known as Theileria annae) has been found to be 
Canine babesiosis

TABLE 1 Geographical spread of canine babesiosis

\begin{tabular}{|c|c|c|c|}
\hline Species of babesia & Tick vector & Country & Endemicity \\
\hline \multicolumn{4}{|l|}{ Large babesia } \\
\hline B. rossi & H. elliptica & South Africa & Endemic \\
\hline B. canis & Dermacentor reticularis & $\begin{array}{l}\text { France } \\
\text { Spain } \\
\text { Hungary } \\
\text { Switzerland } \\
\text { Germany } \\
\text { Belgium } \\
\text { Netherlands }\end{array}$ & $\begin{array}{l}\text { Endemic } \\
\text { Endemic } \\
\text { Endemic } \\
\text { Small outbreaks } \\
\text { Small outbreak } \\
\text { Three cases } \\
\text { Small outbreak }\end{array}$ \\
\hline B. vogeli & R. sanguineus & $\begin{array}{l}\text { USA } \\
\text { Okinawa, Japan } \\
\text { France } \\
\text { Australia } \\
\text { South Africa } \\
\text { Brazil }\end{array}$ & $\begin{array}{l}\text { Endemic in the south, especially in kennels, } \\
\text { but spreading } \\
\text { Endemic } \\
\text { Sample from one dog } \\
\text { Endemic } \\
\text { Endemic } \\
\text { Endemic }\end{array}$ \\
\hline \multicolumn{4}{|l|}{ Small babesia } \\
\hline $\begin{array}{r}\text { B. gibsoni- Californian } \\
\text { isolate }\end{array}$ & $\begin{array}{l}\text { H. bispinosa and } \\
\text { H. longicornis }\end{array}$ & USA & Endemic in the west \\
\hline $\begin{array}{r}\text { B. gibsoni - Asian } \\
\text { isolate }\end{array}$ & & $\begin{array}{l}\text { USA } \\
\text { North and East Africa } \\
\text { Asia } \\
\text { Australia } \\
\text { Middle East } \\
\text { Hungary } \\
\text { Italy }\end{array}$ & $\begin{array}{l}\text { Endemic, spreading northwards (detected in } \\
29 \text { states) } \\
\text { Endemic } \\
\text { Endemic } \\
\text { Three Pitbull Terriers } \\
\text { Endemic } \\
\text { Two dogs (no PCR confirmation) } \\
\text { One case (no PCR confirmation) }\end{array}$ \\
\hline B. annae & & Spain & Endemic \\
\hline
\end{tabular}

endemic in dogs in northwest Spain (Camacho, Pallas, Gestal, Guitan, Olmeda, Telford \& Spielman 2003). Most recently another small piroplasm causing a disease dubbed 'bloody ears' has been identified in Brazil (Loretti \& Barros 2005).

Various species of ticks such as Rhipicephalus sanguineus, Dermacentor spp. and Haemaphysalis ellipticum can transmit the large babesia of dogs, whereas $B$. gibsoni is transmitted by Haemaphysalis bispinosa and Haemaphysalis longicornis. Babesia annae is thought to be transmitted by Ixodes hexagonus (Lobetti 2006). Both trans-stadial and transovarial transmission can occur and ticks are believed to remain infective for several generations. Babesia spp. can also be transmitted by blood transfusion. Strong circumstantial evidence exist that $B$. gibsoni is transmitted by dog bites (Birkenheuer, Correa, Levy \& Breitschwerdt 2005), whilst transplacental transmission from dam to offspring has recently been proven as an additional mode of transmission (Fukumoto, Suzuki, Igarashi \& Xuan 2005).

\section{PATHOGENESIS AND CLINICAL SIGNS}

Babesia spp. cause disease mostly in young dogs, although dogs of all ages can be affected. The incubation period of canine babesiosis varies from 1021 days for $B$. canis and 14-28 days for B. gibsoni. The female ticks feed on their host for about one week only and have left the host by the time disease develops.

The severity of the disease depends on the species of Babesia, the presence of concurrent infections and the age and immune status of the host. The disease presentation varies widely from peracute to chronic or even subclinical. Babesia rossi, the dom- 
inant species found in South Africa, is very virulent and causes peracute and acute disease.

Clinical signs include pale mucous membranes, depression, tachycardia, tachypnoea, anorexia, weakness, splenomegaly and fever. It is thought that the clinical signs are the result of tissue hypoxia following the anaemia and a concomitant systemic inflammatory response syndrome caused by marked cytokine release (Lobetti 2006). The pathogenesis of the anaemia is incompletely understood; intravascular and extravascular haemolysis take place, but other mechanisms such as poor bone marrow response are thought to play a role as well. The anaemia is (perhaps counter-intuitively) not correlated to the degree of parasitaemia and dogs start to improve after parasiticidal treatment, even though their haematocrits generally drop further, before starting to rise (Jacobson, Reyers, Berry \& Viljoen 1996). Some cases show additional immune-mediated breakdown of red blood cells and dogs that show in-saline-positive red blood cell agglutination have to be carefully monitored for rapid decreases in haematocrit. Mortality for Babesia spp. infections range from around $12 \%$ for $B$. rossi to approximately $1 \%$ for $B$. vogeli (Lobetti 2006).

The severe form of the disease is characterized by marked haemolytic anaemia, severe acid-base abnormalities (Leisewitz, Jacobson, De Morais \& Reyers 2001) with frequent secondary multiple organ failure and complications such as acute renal failure (ARF), hepatopathy with marked icterus, hypoglycaemia (Keller, Jacobson, Nel, De Clerq, Thompson \& Schoeman 2004), acute respiratory distress syndrome (ARDS), cerebral pathology and additional immune-mediated red blood cell destruction (IMHA) (Jacobson 2006).

A small subset of dogs presents with high haematocrits (relative haemoconcentration), despite vigorous haemolysis, due to presumed shifting of fluid from the intravascular to the extravascular component. These dogs are at increased risk of developing ARF or cerebral complications, as well as other organ failures (Welzl, Leisewitz, Jacobson, VaughanScott \& Myburgh 2001).

Pancreatitis is frequently associated with other complications, and has a mortality rate of $20 \%$. Icterus, vomition, melaena, abdominal pain and diarrhoea are common findings in dogs with suspected pancreatitis. In addition, $65 \%$ of the dogs with pancreatitis also had icterus, $30 \%$ had ARDS, $30 \%$ had IMHA, $15 \%$ had ARF, while $10 \%$ had haemoconcentration and another $10 \%$ had cerebral syndrome concomitant with the pancreatitis. It is postulated that pancreatitis is the formerly described 'gut' form of babesiosis (Mohr, Lobetti \& Van der Lugt 2000).

Babesia vogeli causes a moderate, often clinically unapparent infection in mature dogs. The parasitaemia in $B$. vogeli also seems to be very low and as such the infection may frequently be missed during the routine examination of a blood smear. Subclinical infections are common in adult dogs infected with $B$. vogeli, but puppies tend to present with marked anaemia (Irwin \& Hutchinson 1991). This is mostly a disease that is endemic in Greyhound kennels in the USA and particular care should be taken when relocating Greyhounds that can harbour subclinical infections.

Babesia canis infections result in a more variable pathogenicity, intermediate between $B$. rossi and $B$. vogeli. A recent study from Italy, presumably describing $B$. canis infection, reported anaemia in the majority of dogs and thrombocytopaenia in all cases (Furlanello, Fiorio, Caldin, Lubas \& Solano-Gallego 2005).

Babesia gibsoni infection may follow a hyper-acute, acute or chronic course. The acute course is the most common, and is characterized by fever, lethargy, haemolytic anaemia, thrombocytopenia, lymphadenopathy and splenomegaly (Conrad, Thomford, Yamane, Whiting, Bosma Uno, Holshuh \& Shelly 1991). The hyper-acute state is rare and is characterized by shock and extensive tissue damage. This is mostly a disease of American Pitbull and Staffordshire Bull Terriers that is putatively transmitted via dog bites (Birkenheuer et al. 2005). Dogs with subclinical $B$. gibsoni infections have been reported in Australia and the USA, where they are PCR positive, but neither show microscopic parasitaemia, nor clinical illness (Maclntire, Boudreaux, West Bourne, Wright \& Conrad 2002). Such cases can have dire consequences if imported into non-endemic areas. Much of the apparent discrepancy in the clinical picture of $B$. gibsoni infections in the USA has lately been explained when distinct genotypical differences have been detected between the Californian and the Asian isolate occurring in the mid-western USA. The Californian isolate seems to be a more virulent species and is found in breeds other than Pitbull Terriers (Kjemtrup et al. 2006).

\section{DIAGNOSIS}

Diagnosis of acute cases infected with $B$. canis is based on the classic clinical presentation and the 
demonstration of the parasites within red blood cells on Diff-quick stained, thin capillary blood smears. The large babesias are typically seen as paired, 2.4 $x 5 \mu \mathrm{m}$-sized bodies, although some red blood cells can contain up to $6-8$ pyriform to round bodies. Babesia gibsoni, the small babesia of dogs, is typically found as single, annular bodies measuring $1 \times 3.2 \mu \mathrm{m}$. The recognition of these small parasites require good staining technique and considerable practice, as many red blood cells in anaemic dogs are vacuolated and pitted. Blood smears are usually taken from the ear margin. The degree of parasitaemia can differ from $0.05-10 \%$ of counted red blood cells, depending on the virulence of the species and has been found to be higher when patients are co-infected with Ehrlichia spp. (Van Heerden, Reyers \& Stewart 1983). Due to the virulence of $B$. rossi, the mere presence of parasites in one red blood cell is enough to confirm the diagnosis. In this species, as well as in $B$. vogeli, parasitaemia has been shown to be higher in capillary than in central blood at presentation (Irwin \& Hutchinson 1991; Böhm, Leisewitz, Thompson \& Schoeman 2006). Ironically, the converse has been shown when a higher parasitaemia was found in central blood rather than capillary blood in dogs experimentally infected with $B$. vogeli (Ewing 1966).

In more chronic cases, due to less virulent species such as $B$. canis and $B$. vogeli, where parasitaemia may be below the microscopic detection limit, diagnosis is more problematic and a presumptive diagnosis is often based on suggestive historical findings, physical examination findings and positive indirect fluorescent antibody titres or PCR. Thick smears (not alcohol fixed) may be helpful in detecting the parasite in cases of very low parasitaemia.

Another way in which to increase the likelihood of finding parasites is to search along the periphery of the blood smear, as parasitized red blood cells tend to marginate during the making of the smear. Recent or active infection can be confirmed by the demonstration of increasing antibody titres over 2-3 weeks. An improved ELISA has recently been developed that is able to distinguish between infection with $B$. gibsoni and the $B$. canis species on serology alone (Verdida, Hara et al. 2004). Some sub-clinical infections require bone marrow aspirate cytology or smears prepared from red cells just below the buffy coat to demonstrate the parasite. A diagnosis should not be based solely on seropositivity, because clinically normal dogs in or from endemic areas can be seropositive. The high sensitivity and specificity of a newly developed PCR probe should allow the de- tection of low parasitaemias in subclinically infected cases and may be the most useful test in screening dogs newly imported into Babesia-free countries.

The rest of the blood smear findings are classically those reflecting the underlying regenerative, haemolytic anaemia and include marked anisocytosis, polychromasia, reticulocytosis and normoblastaemia. It takes the bone marrow approximately 3-5 days to respond to an acute red blood cell breakdown and, therefore, the blood smear findings in acute cases may appear to reflect those of a nonregenerative anaemia. Thrombocytopenia is a hallmark of the disease, regardless of the Babesia spp. involved and is often marked, but yet petechiation or epistaxis is very rarely seen, except in cases with concomitant Ehrlichia infections (Furlanello et al. 2005; Kettner, Reyers \& Miller 2003). The pathophysiology of the thrombocytopenia remains undetermined, but sequestration or consumption is postulated.

Other haematological findings may include spherocytosis, in cases with secondary immune-mediated haemolytic anaemia and a left shift neutrophilia due to the marked systemic inflammatory response. Acute babesiosis can easily be misdiagnosed as primary immune-mediated haemolytic anaemia, especially if parasitaemias are low, only central venous blood is submitted or when laboratory personnel and clinicians are unfamiliar with the appearance of the parasites. In this regard a positive antiglobulin (Coombs' test) may add to the confusion, since most $B$. canis and $B$. gibsoni infected dogs have been found to be positive with this test. The same diagnostic conundrum has been found in $B$. gibsoni-infected cases with thrombocytopenia, in the absence of detectable parasitaemia. It is important to remember that thrombocytopenia in these infections precedes the onset of anaemia and parasitaemia.

Further laboratory findings include elevation of liver enzymes such as ALP, ALT and AST-more so in the patients with marked icterus, reflecting the concomitant hepatopathy in these cases. Serum potassium is often low, especially in icteric cases. Serum bilirubin concentrations are elevated, commensurate with the degree and rapidity of onset of the anaemia and the severity of the accompanying hepatopathy. Azotaemia is present in many dehydrated cases and in those with acute renal failure (Lobetti \& Jacobson 2001). Urea is frequently disproportionately raised to creatinine and is elevated for reasons other than renal disease (De Scally, Leisewitz, Lobetti \& Thompson 2006). Urinalysis may show bili- 
rubinuria, haemoglobinuria, proteinuria, renal tubular epithelial cells and granular casts.

Acid base abnormalities are common with metabolic acidosis (due to raised lactate and raised chloride ion concentration) and respiratory alkalosis being most common. Severe disease almost always causes mixed acid base imbalances (Leisewitz et al. 2001).

\section{TREATMENT}

The primary goals are to eliminate the parasite and reverse the life-threatening anaemia. Diminazene aceturate, trypan blue and imidocarb dipropionate are effective against $B$. canis (Table 2). Mildly to moderately affected dogs normally make an uneventful recovery following antibabesial therapy alone. The epidemiology of the disease seems to suggest that dogs do develop a state of premunition after repeated infections. However, in non-endemic areas, it would be ideal to sterilise the infection and therefore render the dogs non-infective for ticks, in order to prevent the organism from becoming established in that country. Imidocarb dipropionate at a dose of either $7.5 \mathrm{mg} / \mathrm{kg}$ once off or $7 \mathrm{mg} / \mathrm{kg}$ given twice with a 14-day interval have been shown to sterilise the infection. Diminazene dose calculation should be meticulous due to its low therapeutic index, especially in puppies and the drug should not be repeated within an interval of shorter than a 3week period (Miller, Swan, Lobetti \& Jacobson 2005). The absolute minimum interval might be longer in certain breeds and individuals, which appear to show a propensity to develop severe cerebral toxicity with classic cerebellar sulci haemorrhages. In the author's experience this complication is fortunately quite rare.
Trypan blue is one of the oldest drugs, but is still used in some parts of the world. Neither diminazene, nor trypan blue is capable of sterilising the infection and their use in non-endemic areas is therefore discouraged.

The first treatment that has been shown to be effective against $B$. gibsoni is a combination of atovaquone and azithromycin (Birkenheuer, Levy \& Breitschwerdt 2004). These parasites are very difficult to clear with conventional therapy and dogs usually become chronic carriers or present with recurrent episodes of acute babesiosis.

Markedly anaemic animals or those with any of the abovementioned complications require a variety of supportive treatments, depending on the severity of the case and range from single to multiple blood transfusions, corticosteroid drug administration for the concomitant immune-mediated red blood cell destruction, aggressive colloidal and crystalloid fluid support with added electrolytes such as potassium chloride and diuretics in cases with acute renal failure. Assisted respiration is frequently necessary for cases with pulmonary oedema due to acute respiratory distress syndrome.

Cross matching is not necessary for the first transfusion in dogs, because dogs do not have naturally occurring allo-antibodies. To further minimize delayed transfusion reactions or the risk of sensitising patients that might invariably require future transfusions in endemic areas, only DEA 1.1 and 1.2 negative donors are used. Whole blood can safely be used in cases of canine babesiosis. The decision to administer a blood transfusion is a multi-facetted one and is not determined solely by the patient's haematocrit, but rather by the clinical condition of the animal and the rapidity of onset of the anaemia.

TABLE 2 Drugs used in the treatment of babesiosis

\begin{tabular}{|l|l|l|l|l|}
\hline Babesia spp. & Drug & Dose & $\begin{array}{l}\text { Route of } \\
\text { administration }\end{array}$ & Duration of therapy \\
\hline B. canis & $\begin{array}{l}\text { Diminazene aceturate } \\
\text { (Berenil囚) }\end{array}$ & $3.5 \mathrm{mg} / \mathrm{kg}$ & IM/SC & One dose \\
\hline B. canis & $\begin{array}{l}\text { Trypan blue } \\
\text { (Trypan blue®) }\end{array}$ & $10 \mathrm{mg} / \mathrm{kg}$ & Strictly IV & $\begin{array}{l}\text { One dose followed by } \\
\text { imidocarb or diminazene } \\
1 \text { week later }\end{array}$ \\
\hline B. canis & $\begin{array}{l}\text { Imidocarb dipropionate } \\
\text { (Imizol®) }\end{array}$ & $7 \mathrm{mg} / \mathrm{kg}$ & IM & $\begin{array}{l}\text { Two doses, } 14 \text { days } \\
\text { apart }\end{array}$ \\
\hline B. gibsoni & $\begin{array}{l}\text { Atovaquone and } \\
\text { Azithromycin }\end{array}$ & $\begin{array}{l}13.3 \mathrm{mg} / \mathrm{kg} \mathrm{q} 8 \mathrm{~h} \\
10 \mathrm{mg} / \mathrm{kg} \mathrm{q} 24 \mathrm{~h}\end{array}$ & $\begin{array}{l}\text { PO } \\
\text { PO consecutive days }\end{array}$ \\
\hline B. felis & Primaquin phosphate & $0.5 \mathrm{mg} / \mathrm{kg}$ & $\mathrm{IM}$ & Daily for $1-3$ days \\
\hline
\end{tabular}


As such, dogs with haematocrits as low as $0.07 \mathrm{l} / \mathrm{\ell}$ can survive without transfusion, whereas some dogs with haematocrits as high as $0.20 \mathrm{l} / \mathrm{l}$ have to be transfused. Given the stringent criteria for donor selection and the significant owner and veterinarian effort needed to procure safe blood, it should be considered a precious resource. Due to this and other equally cogent arguments, the use of component therapy (i.e. red blood cells or plasma) has gained favour, allowing a single unit of blood to meet the needs of several patients. Acute canine babesiosis cases are not necessarily volume depleted and mostly require oxygen-carrying capacity only (in some cases with ARF or ARDS volume expansion may actually be harmful), and thus benefit most from the use of packed red blood cells. Blood is initially transfused slowly $(2 \mathrm{ml} / \mathrm{kg} / \mathrm{h})$ for the first 30-60 min, while observing the patients for transfusion reactions, such as a sudden rise in body temperature and/or respiratory rate and lip and ear pinna swelling.

\section{PROGNOSIS}

The prognosis is generally quite good, with approximately $85-90 \%$ of cases surviving the illness, depending on the level of care and the Babesia spp. Involved (Keller et al. 2004; Schoeman, Rees \& Herrtage 2007). The use of blood transfusions has a major impact on survival in severely anaemia animals. Cases with haemoconcentrated babesiosis and cases developing acute renal failure, acute respiratory distress syndrome or cerebral babesiosis have the worst prognosis and mortality can be greater than $50 \%$-in some cases approaching $100 \%$, despite intensive, technically advanced interventions (Welzl et al. 2001).

Lactate concentrations of $>5 \mathrm{mmol} / \ell$ on admission are associated with increased mortality, but lactate $>2.5 \mathrm{mmol} / \ell$ and/or increase after admission and/or failure to decrease to $<50 \%$ of admission value, is strongly predictive of death. Lactate persistently $>4.4 \mathrm{mmol} / \ell$ strongly predicts death and lactate $>4.4 \mathrm{mmol} / \mathrm{\ell}$ at $24 \mathrm{~h}$ after admission correctly predicts death in every case. Hyperlactataemia is present in approximately half of hospitalised cases. Extremely high values $(>10 \mathrm{mmol} / \ell)$ are not uncommon. Lactate correlates negatively with glucose. Hyperlactataemia is also positively associated with clinical collapse (Nel, Lobetti, Keller \& Thompson 2004).

Acute renal failure (ARF) is rare. Renal involvement in babesiosis is diagnosed on the basis of persistently elevated creatinine despite appropriate fluid therapy. Renal involvement in babesiosis resembles the functional renal failure of sepsis. Oliguria is an ominous sign (Lobetti \& Jacobson 2001).

Hypotension is common in babesiosis and is associated with clinical collapse (Jacobson, Lobetti \& Vaughan-Scott 2000). Clinical collapse is also associated with hypoglycaemia (Keller et al. 2004). This appears to be a very simple and useful prognostic factor (Böhm et al. 2006).

A small study, comparing 3 dogs that died naturally with 31 other dogs, showed higher cardiac troponin I values in the non-survivors. This suggested that high cardiac troponin I values are associated with a poor outcome. From these results, cTnl also correlated with disease severity (Lobetti, Dvir \& Pearson 2002).

Hypoglycaemia (glucose $<3.3 \mathrm{mmol} / \ell$ ) is present in c. $20 \%$ of cases. Hypoglycaemia is associated with stupor and collapse. Miosis disappears after dextrose infusion. Dogs that are collapsed (non-ambulatory) at presentation have an 18-fold increased risk for hypoglycaemia. Pups less than 6 months of age are at risk of developing hypoglycaemia. The risk is slightly increased in dogs with severe anaemia, icterus or vomition. Response to treatment with intravenous dextrose is sometimes dramatic. Hypoglycaemia is an important differential diagnosis for cerebral babesiosis. When glycaemic status is taken into account, the incidence of true cerebral babesiosis is very low (Keller et al. 2004).

Timing, source of blood (venous versus capillary) and counting method cause large variability in parasite counts. A significant positive correlation between high parasitemia and mortality has recently been demonstrated. There is also a significant positive correlation between capillary and venous parasitaemia, with capillary parasitaemias being consistently higher than venous ones, making the capillary the preferential site for obtaining diagnostic smears (Böhm et al. 2006).

At presentation to the hospital, dogs that died had a significantly higher median cortisol concentration $(482 \mathrm{nmol} / \ell)$ than other admitted dogs that survived $(150 \mathrm{nmol} / \ell)$. Conversely, the total and free thyroxine concentrations in all but one of the dogs that died were below the limit of detection and significantly lower $(2.7 \mathrm{nmol} / \ell$ and $0.12 \mathrm{pmol} / \ell$, respectively) than in other admitted dogs that survived (7.4 $\mathrm{nmol} / \ell$ and $0.4 \mathrm{pmol} / \ell$, respectively). Six of 11 dogs $(55 \%)$ with a serum cortisol above $400 \mathrm{nmol} / \ell \mathrm{died}$, whereas all dogs with admission serum cortisol concentrations less than $260 \mathrm{nmol} / \ell$ survived (Schoe- 
man et al. 2007). In addition, dogs that died also had increased ACTH-stimulated cortisol concentrations, indicating that acute up-regulation of adrenal function is associated with poor outcome (Schoeman \& Herrtage 2008).

Outcome is not affected by systemic inflammatory response syndrome (SIRS) and multiple organ dysfunction syndrome positive status, nor the number of organs involved, but rather by the organ system affected, such as the lungs, kidneys or brain (Welzl et al. 2001).

\section{PREVENTION}

Regular control of the tick vectors by routinely dipping or spraying pets or using tick collars or spot-on preparations is the only effective way of preventing this disease in most parts of the world. Ticks must feed on the host for at least 3 days in order to transmit $B$. rossi and owners should therefore be encouraged to examine their dogs daily for the presence of ticks. A vaccine against $B$. rossi has recently become commercially available in South Africa (Nobivac Piro $\AA$ ) and research into developing vaccines for all species of canine babesiosis is ongoing. Blood donors in endemic areas should be regularly tested to prevent the spread of the disease via blood transfusion.

\section{ACKNOWLEDGEMENTS}

Acknowledgement is due to all the lecturers and residents, past and present, at the Department of Companion Animal Clinical Studies at Onderstepoort and to all tireless babesiosis researchers worldwide, who have over many years contributed to the knowledge base that the author was able to draw from.

\section{REFERENCES}

BIRKENHEUER, A.J., LEVY, M.G. \& BREITSCHWERDT, E.B. 2004. Efficacy of combined atovaquone and azithromycin for therapy of chronic Babesia gibsoni (Asian genotype) infections in dogs. Journal of Veterinary Internal Medicine, 18: 494-498.

BIRKENHEUER, A.J., NEEL, J., RUSLANDER, D., LEVY, M.G. \& BREITSCHWERDT, E.B. 2004. Detection and molecular characterization of a novel large Babesia species in a dog. Veterinary Parasitology, 124:151-160.

BIRKENHEUER, A.J., CORREA, M.T., LEVY, M.G. \& BREITSCHWERDT, E.B. 2005. Geographic distribution of babesiosis among dogs in the United States and association with dog bites: 150 cases (2000-2003). Journal of the American Veterinary Medical Association, 227:942-947.

BÖHM, M., LEISEWITZ, A.L., THOMPSON, P.N. \& SCHOEMAN, J.P. 2006. Capillary and venous Babesia canis rossi parasi- taemias and their association with outcome of infection and circulatory compromise. Veterinary Parasitology, 141:18-29.

CAMACHO, A.T., PALLAS, E., GESTAL, J.J., GUITIAN, F.J., OLMEDA, A.S., TELFORD, S.R. \& SPIELMAN, A. 2003. Ixodes hexagonus is the main candidate as vector of Theileria annae in northwest Spain. Veterinary Parasitology, 112:157163.

CONRAD, P., THOMFORD, J., YAMANE, I., WHITING, J., BOSMA, L., UNO, T., HOLSHUH, H.J. \& SHELLY, S. 1991. Hemolytic anemia caused by Babesia gibsoni infection in dogs. Journal of the American Veterinary Medical Association, 199:601-605.

DE SCALLY, M.P., LEISEWITZ, A.L., LOBETTI, R.G. \& THOMPSON, P.N. 2006. The elevated serum urea:creatinine ratio in canine babesiosis in South Africa is not of renal origin. Journal of the South African Veterinary Association, 77:175-178.

EWING, S.A. 1966. Evaluation of methods used to detect Babesia canis infections in dogs. Cornell Veterinarian, 56:211-220.

FUKUMOTO, S., SUZUKI, H., IGARASHI, I. \& XUAN, X. 2005. Fatal experimental transplacental Babesia gibsoni infections in dogs. International Journal for Parasitology, 35:10311035.

FURLANELLO, T., FIORIO, F., CALDIN, M., LUBAS, G. \& SOLANO-GALLEGO, L. 2005. Clinicopathological findings in naturally occurring cases of babesiosis caused by large form Babesia from dogs of northeastern Italy. Veterinary Parasitology, 134:77-85.

IRWIN, P.J. \& HUTCHINSON, G.W. 1991. Clinical and pathological findings of Babesia infection in dogs. Australian Veterinary Journal, 68:204-209.

JACOBSON, L.S., REYERS, F., BERRY, W.L. \& VILJOEN, E. 1996. Changes in haematocrit after treatment of uncomplicated canine babesiosis: a comparison between diminazene and trypan blue, and an evaluation of the influence of parasitaemia. Journal of the South African Veterinary Association, 67:77-82.

JACOBSON, L.S., LOBETTI, R.G. \& VAUGHAN-SCOTT, T. 2000. Blood pressure changes in dogs with babesiosis. Journal of the South African Veterinary Association, 71:1420.

JACOBSON, L.S. 2006. The South African form of severe and complicated canine babesiosis: clinical advances 1994-2004. Veterinary Parasitology, 138:126-139.

KELLER, N., JACOBSON, L.S., NEL, M., DE CLERQ, M., THOMPSON, P.N. \& SCHOEMAN, J.P. 2004. Prevalence and risk factors of hypoglycemia in virulent canine babesiosis. Journal of Veterinary Internal Medicine, 18:265-270.

KETTNER, F., REYERS, F. \& MILLER, D. 2003. Thrombocytopaenia in canine babesiosis and its clinical usefulness. Journal of the South African Veterinary Association, 74:63-68.

KJEMTRUP, A.M., WAINWRIGHT, K., MILLER, M., PENZHORN, B.L. \& CARRENO, R.A. 2006. Babesia conradae, sp. nov., a small canine Babesia identified in California. Veterinary Parasitology, 138:103-111.

LEISEWITZ, A.L., JACOBSON, L.S., DE MORAIS, H.S. \& REYERS, F. 2001. The mixed acid-base disturbances of severe canine babesiosis. Journal of Veterinary Internal Medicine, 15:445-452.

LOBETTI, R.G. \& JACOBSON, L.S. 2001. Renal involvement in dogs with babesiosis. Journal of the South African Veterinary Association, 72:23-28.

LOBETTI, R.G., DVIR, E. \& PEARSON, J. 2002. Cardiac troponins in canine babesiosis. Journal of Veterinary Internal Medicine, 16:63-68. 
LOBETTI, R.G. 2006. Babesiosis, in Infectious diseases of the dog and cat, $3^{\text {rd }}$ ed., edited by C.E. Greene. Philadelphia: W.B. Saunders.

LORETTI, A.P. \& BARROS, S.S. 2005. Hemorrhagic disease in dogs infected with an unclassified intraendothelial piroplasm in southern Brazil. Veterinary Parasitology, 134:193-213.

MACINTIRE, D.K., BOUDREAUX, M.K., WEST, G.D., BOURNE, C., WRIGHT, J.C. \& CONRAD, P.A. 2002. Babesia gibsoni infection among dogs in the southeastern United States. Journal of the American Veterinary Medical Association, 220:325-329.

MATJILA, P.T., PENZHORN, B.L., BEKKER, C.P., NIJHOF, A.M. \& JONGEJAN, F. 2004. Confirmation of occurrence of Babesia canis vogeli in domestic dogs in South Africa. Veterinary Parasitology, 122:119-125.

MATJILA, P.T., LEISEWITZ, A.L., JONGEJAN, F. \& PENZHORN, B.L. 2008. Molecular detection of tick-borne protozoal and ehrlichial infections in domestic dogs in South Africa. Veterinary Parasitology, 155:152-157.

MILLER, D.B., SWAN, G.E., LOBETTI, R.G. \& JACOBSON, L.S. 2005. The pharmacokinetics of diminazene aceturate after intramuscular administration in healthy dogs. Journal of the South African Veterinary Association, 76:146-150.

MOHR, A.J., LOBETTI, R.G. \& VAN DER LUGT, J.J. 2000. Acute pancreatitis: a newly recognised potential complication of canine babesiosis. Journal of the South African Veterinary Association, 71:232-239.

MUHLNICKEL, C.J., JEFFERIES, R., MORGAN-RYAN, U.M. \& IRWIN, P.J. 2002. Babesia gibsoni infection in three dogs in Victoria. Australian Veterinary Journal, 80:606-610.
NEL, M., LOBETTI, R.G., KELLER, N. \& THOMPSON, P.N. 2004. Prognostic value of blood lactate, blood glucose and hematocrit in canine babesiosis. Journal of Veterinary Internal Medicine, 18:471-476.

SCHOEMAN, J.P., REES, P. \& HERRTAGE, M.E. 2007. Endocrine predictors of mortality in canine babesiosis caused by Babesia canis rossi. Veterinary Parasitology, 148:75-82.

SCHOEMAN, J.P. \& HERRTAGE, M.E. 2008. Adrenal response to the low dose ACTH stimulation test and the cortisol-toadrenocorticotrophic hormone ratio in canine babesiosis. Veterinary Parasitology, 154:205-213.

UILENBERG, G., FRANSSEN, F.F., PERIE, N.M., \& SPANJER, A.A. 1989. Three groups of Babesia canis distinguished and a proposal for nomenclature. Veterinary Quarterly, 11:33-40.

VAN HEERDEN, J., REYERS, F., \& STEWART, C.G. 1983. Treatment and thrombocyte levels in experimentally induced canine ehrlichiosis and canine babesiosis. Onderstepoort Journal of Veterinary Research, 50:267-270.

VERDIDA, R.A., HARA, O.A., XUAN, X., FUKUMOTO, S., IGARASHI, I., ZHANG, S., DONG, J., INOKUMA, H., KABEYA, H., SATO, Y., MORITOMO, T., MARUYAMA, S., CLAVERIA, F. \& NAGASAWA, H. 2004. Serodiagnosis of Babesia gibsoni infection in dogs by an improved enzyme-linked immunosorbent assay with recombinant truncated P50. Journal of Veterinary Medical Science, 66:1517-1521.

WELZL, C., LEISEWITZ, A.L., JACOBSON, L.S., VAUGHANSCOTT, T. \& MYBURGH, E. 2001. Systemic inflammatory response syndrome and multiple-organ damage/dysfunction in complicated canine babesiosis. Journal of the South African Veterinary Association, 72:158-162. 